\title{
The Construction of University's Smart Library
}

\author{
Haibo Zhang ${ }^{1, a}$, Peifa $\operatorname{Lin}^{2, b}$ and Xiaoyan $\mathrm{Li}^{3, \mathrm{c}}$ \\ 1,2,3 Library, Beijing Institute of Fashion Technology; Beijing 100029, China \\ ahbdmzhb@126.com, b peking99@bift.edu.cn, ${ }^{\mathrm{c}} \mathrm{ddb} 301 @ 163 . c o m$
}

\section{Keywords: Smart Library; Library Service; Big Data; Algorithm}

\begin{abstract}
Due to the limitation of objective conditions, some university libraries can hardly change their "physical conditions" such as library buildings. In order to improve service quality, it is an effective method to use information technology to build "virtual conditions" of libraries. As an important content of "virtual conditions," the construction of a smart library has a direct impact on the level of library management and service. Although the construction of smart libraries has achieved some initial results, it also faces a series of problems. This article sets out from the basic tenet of the library and puts forward that: for the readers, the smart library must be "I understand you"; for the librarians or managers, the smart library must be "I help you". At the same time, it also put forward several remarks on how to build a smart library. Finally, combining the actual situation of the library of our school, we put forward two construction directions that can be implemented at present.
\end{abstract}

\section{Why We Should Build a Smart Library}

Before discussing the smart library, we must first understand the basic purpose of the library. Literature [1] believes that libraries should adhere to the principle of "people-oriented" and regard readers' needs and high-quality services as the starting point and destination. Literature [2] holds that libraries are the best tools and methods for people to actively acquire knowledge. Paper [3] argues that all for readers is the fundamental purpose of library work. In short, simply speaking, the purpose of the library is inseparable from the service. The most basic purpose of the library is service.

Of course, there are good and bad services. "Face is ugly, things are difficult to do" is a service. "Reader first, service supremacy" is also a service. The majority of library librarians are subjectively looking forward to providing good services, so they want to achieve "Reader first, service supremacy ". Therefore, after they pay full enthusiasm and hard work, it will surely gain readers' recognition. But sometimes it is not satisfactory. For example, what the librarians wants to provide and what they can provide may not necessarily be what the readers need. What the readers themselves needs may not be quickly and effectively found in the library. All these problems can be solved by building a smart library.

\section{What is a Smart Library}

So far, for what is a smart library, our library science community has not reached a consensus. Literature [5] earlier proposed the concept of a smart library: a smart library refers to a library model that uses its new generation of information technology to change the interaction between user and library system information resources and realizes its intelligent service and management. In addition, the meaning of smart libraries described by others is mostly based on the perspective of information technology and intelligence services [6-8].

This article combines the current research status and integrates some views or viewpoints [9-10]. It holds that the core of the smart library is the integration of books and related data, as well as digital and space resources, based on the realization of comprehensive informationization of the library. Use of large data intelligent analysis platform, the library management and services are intelligent and personalized, and the reader needs are oriented to improve their experience. To 
achieve this, the construction of a smart library requires the realization of a true full data exchange and the availability of a full-scale data-sharing center. At the same time, data must be processed and services must be provided. In turn, processes and services can promote data appreciation; On the basis of integrating and combing structured data, semi-structured data, and unstructured data, seek or mine the value of big data through "structured data + semi-structured data + unstructured data + big data analysis platform"; The library realizes the "people-oriented" service concept, better provides readers with "intelligent" services, and provides relevant "wisdom" decision support for management.

Therefore, the most fundamental purpose of the library having a certain "wisdom" is to provide readers with more excellent services, and also provides decision-making services to the managers and librarians. The ultimate goal of decision-making services is still to provide readers with better services. How can it be considered to provide readers with quality services? The answer is three words, "I understand you." Only when the library can "understand" the readers but only has certain "good" wisdom, can it truly reflect the service philosophy of "people-oriented, readers first", It can truly let the reader to experience the sense of "home study", and can better interact with the reader to better allow readers to acquire more knowledge actively or passively. Then how can we provide "decision-making services for managers and librarians"? It's also three word, "I help you." It is the smart library to help managers provide relevant management decisions and help librarians provide readers with quality services.

\section{How to Build a Smart Library}

Basing on understand the concept of a smart library and clarify the most fundamental purpose of building a smart library, in order to make the smart library truly "I understand you" and "I help you”, this paper believes that the following five aspects are needed:

First, there is demand. The demand is what do you want to do? What do you want to do? The construction of a smart library involves many aspects, many levels, and many technologies. It is not possible for a library to fully realize "smartness" all at once. It is not possible to put one step in place because other library needs may not be your needs. The smart library that others understand is not necessarily the same as you understand. Therefore, we must clarify our own needs what is a prerequisite for building a smart library. For example, for a university library, the purchase of books and e-books, under the premise of a certain amount of funds, how to allocate the purchase of books and e-books in order to achieve the maximum effectiveness or optimal results? When buying books or e-books in a specific way, what professional, what publisher, Chinese or foreign language, etc., can be purchased to maximize the satisfaction of readers? All of these issues need to be considered in the light of the college's funding situation, discipline development, and specialties and other factors. It is impossible to completely introduce the success stories of other universities. Therefore, to build a smart library, for university libraries, they must first understand and clarify the "wisdom" needs of teachers, students, colleges, librarians, etc., and build a smart library based on these demands.

Second, there is data. In the premise of demand, relevant data must be supported. A smart library without data is like "a passive water." For example, if the library wants to analyze the relationship between readers' borrowing information and readers' academic performance, then there is no reader's academic record. Therefore, the data must meet the needs of building a smart library, not only the data generated by the library's information system, but also the data of other business systems in colleges and universities. In addition, the data is generally structured data and unstructured data. The structured data is easy to understand, such as the student's student number, age, class, and other numbers or text information. Unstructured data includes many, such as office documents and texts, pictures, XML, HTML, various reports, images and audio/video information, etc. Therefore, with data, there must be a management platform for big data. Otherwise, the management of data could not be implemented at all, let alone data analysis.

Third, there is an algorithm. Having definite requirements, and the corresponding data, then how 
to achieve wisdom? There must be an algorithm. Of course, some algorithms are still intelligent algorithms. The construction of a smart library needs to give "wisdom" to computers that only understand " 0 " and " 1 ." According to the current computer architecture, algorithms and intelligent algorithms can only be used to achieve this. Of course, there are many algorithms. Only after clarifying the requirements and obtaining relevant data, can we choose the right algorithm to achieve "wisdom".

Fourth, there is some people. For university libraries, the "people" here include the managers of the library (the curator, the leaders of the college), all the librarians, and the readers. To build a smart library, these people must make concerted efforts and work together. All the three people are indispensable. Literature [11] holds that the curator is the core of library management, the curator's sense of innovation determines the process of library reform. The service is the bounden duty of the librarian, and the reform and innovation are the driving force for comprehensively improving the service quality of the library. In the construction of the smart library, the role of the manager is mainly the leader of the construction, the person responsible for project implementation, the decision makers of various needs, and the supporters of all the work. The role of the librarian is mainly the implementer of the project, the proponents of demand, service providers, etc. The librarians who directly responsible for the construction of smart libraries must understand and master the corresponding computer technologies such as databases, artificial intelligence, big data, and intelligence algorithms, software development and other related knowledge. Of course, the construction of a smart library is also inseparable from the majority of readers. Their main role is "God." Their satisfaction with the services is not only the key to the success or failure of the construction of smart libraries.

Fifth, there is money. Without the support of sufficient funds, the building of the Smart Library cannot take place.

\section{Development Suggestions}

The construction of a smart library does not happen overnight. When considering how to build a smart library, we need to consider the actual situation of the library. As of the end of 2017, our library has more than 1 million 92 thousand books (items) of collections in different disciplines and languages, more than 900 Chinese and foreign language periodicals, and 3 million electronic books, about 50,000 kinds of electronic journals that directly access the full text, more than 20,000 multimedia materials, and more than 80 various database systems, which basically meet the needs of teaching and scientific research. In the early days of the construction of the smart library, it was proposed to continue to increase the types and quantity of electronic resources on the one hand; on the other hand, from one or several points, combined with the latest technologies such as artificial intelligence and big data to improve management and service levels.

The library of our university has always attached great importance to the construction of library electronic resources. In the construction of electronic resources, more consideration is given to providing teachers and students with more excellent services. For example, in October 2017, the nation's first university fabric library was established, with 1 million physical sample cards, realizing the effective combination of physical and electronic resources, and providing services both inside and outside the college.

In the use of the latest information technology, combined with the actual situation of our library, we can now consider two aspects: First, in order to improve the borrow rate of paper books, consider the use of artificial intelligence and big data technology to establish intelligent procurement model, instead of the original manual purchase method to achieve intelligent paper book procurement. The second is to use visualization and big data technology to create a visualized intelligent library management and service platform to achieve visual data management and improve management. 


\section{Conclusion}

In short, the building of a smart library can be likened to the growth of a person. "Demand" can be compared to the person's brain. What kind of person this person wants to be is determined by the brain. "Data" is flesh and blood, "Algorithms" are skeletons, " "People" is the teacher and leader of this person. "Money" is the person's living expenses.

In the construction of a smart library, the five factors are both independent and interconnected, and they are indispensable. Only five factors coordinated with each other and harmonious progress can make the library achieve certain "intelligence." Here, "certain" refers to a level. In the future, with the development of technology, a smart library will be more "wisdom" and eventually realize "I understand you" and "I help you" in the true sense.

\section{Acknowledgement}

In this paper, the research was sponsored by the the Teaching Reform Key Project of Beijing Institute of Fashion Technology (Project No. ZDJG-1510).

\section{References}

[1] Yan Puyao. People-oriented: the Purpose of University Library[J]. Value Engineering, 2012,31(06):264-265.

[2] Wang Z izhou. What is the Tenet of the Science of Library[J]. Library, 2001,(01):10-14.

[3] Zhao Zhenping, Yuang Jikun. Everything for readers is the fundamental aim of library work [J]. Journal of Academic Library and Information Science, 1996,(04):47-49.

[4] http://www.360doc.cn/mip/537809147.html[EB]

[5] Yang Dong. Internet of Things-based Smart Library[J] . Journal of Library Science, 2010(07):8-10. (In Chinese)

[6] Chu Jiewang, Li An. Construction of Smart Library and its Requirements for Technology and Librarians [J]. Library and Information Service, 2015(15):27-34.

[7] Wang Shiwei. On Three Main Features of the Smart Library[J]. Journal of Library Science in China, 2012(06):22-28.

[8] Yao Chuanjun. Sci-Tech Information Development \& Economy[J]. Sci-Tech Information Development \& Economy, 2015(22):159-160.

[9] Xu Tiancai, Yang Xin,Tian Lin. Exploration Course of Independent Innovation Oriented Academic Library-Taking Chongqing University Libraryas an Example [J]. Library Tribun,2017,37(04):9-17.

[10]Ceng Ziming, Jin Peng. Research on the Service System and Service Mode of Personalized Recommendation in Smart Library[J]. Library Journal,2015,34(12):16-22.

[11]Cheng Huanwen, Wang Lei. The New Ideals of Academic Library Management in the 21st Century[J]. Journal of Academic Libraries, 2003,(02):15-21. 